\title{
Erratum to: Self-reported flares are predictors of radiographic progression in rheumatoid arthritis patients in 28-joint disease activity score remission: a 24-month observational study
}

Francesca Ometto ${ }^{1}$, Bernd Raffeiner ${ }^{1,2}$, Livio Bernardi ${ }^{1}$, Costantino Botsios ${ }^{1}$, Nicola Veronese ${ }^{3,4}$, Leonardo Punzi ${ }^{1}$ and Andrea Doria ${ }^{1 *}$

Unfortunately, after publication of this article [1], it was noticed that the author name Constantino Botsios was incorrectly spelled during the production process. The corrected name can be seen in the author list above and the original article has also been updated to reflect this.

\begin{abstract}
Author details
${ }^{1}$ Rheumatology Unit, Department of Medicine, University of Padova, Via Giustiniani, 2, Padova 35128, Italy. ${ }^{2}$ Rheumatology Unit, Department of Medicine, Bolzano General Hospital, Via Lorenz Bohler, 5, Bolzano 39100, Italy.

${ }^{3}$ Department of Medicine, University of Padova, Via Giustiniani, 2, Padova 35128 , Italy. ${ }^{4}$ Institute of clinical Research and Education in Medicine (IREM), Padova, Italy.
\end{abstract}

Received: 10 May 2016 Accepted: 11 May 2016

Published online: 23 May 2016

\section{Reference}

1. Ometto F, Raffeiner B, Bernardi L, Botsios C, Veronese N, Punzi L, Doria A, et al. Self-reported flares are predictors of radiographic progression in rheumatoid arthritis patients in 28-joint disease activity score remission: a 24-month observational study. Arthritis Res Ther. 2016;18:89. doi:10.1186/s13075-016-0986-1.

\footnotetext{
* Correspondence: adoria@unipd.it

${ }^{1}$ Rheumatology Unit, Department of Medicine, University of Padova, Via Giustiniani, 2, Padova 35128, Italy

Full list of author information is available at the end of the article

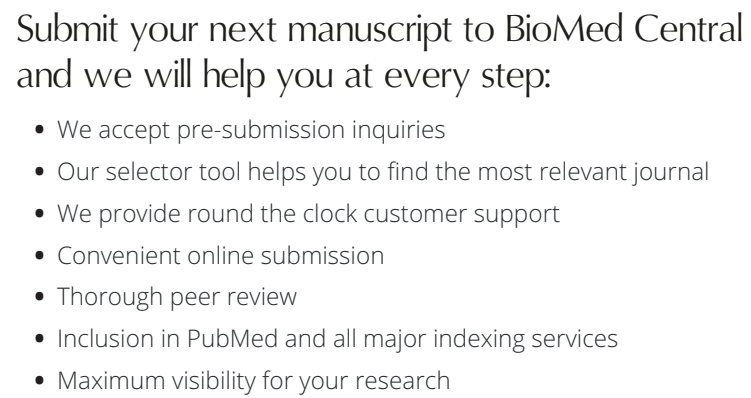

- We accept pre-submission inquiries

- Our selector tool helps you to find the most relevant journal

- We provide round the clock customer support

- Convenient online submission

- Thorough peer review

- Inclusion in PubMed and all major indexing services

- Maximum visibility for your research

Submit your manuscript at www.biomedcentral.com/submit 